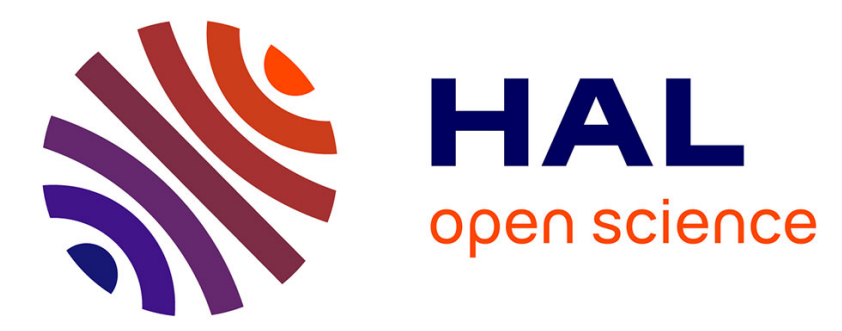

\title{
A Conceptual Review of Social Media Adoption in SMEs
}

Hanaa Namankani, Claire Moxham, Matthew Tickle

\section{To cite this version:}

Hanaa Namankani, Claire Moxham, Matthew Tickle. A Conceptual Review of Social Media Adoption in SMEs. 15th Conference on e-Business, e-Services and e-Society (I3E), Sep 2016, Swansea, United Kingdom. pp.240-250, 10.1007/978-3-319-45234-0_22 . hal-01702176

\section{HAL Id: hal-01702176 \\ https://hal.inria.fr/hal-01702176}

Submitted on 6 Feb 2018

HAL is a multi-disciplinary open access archive for the deposit and dissemination of scientific research documents, whether they are published or not. The documents may come from teaching and research institutions in France or abroad, or from public or private research centers.
L'archive ouverte pluridisciplinaire HAL, est destinée au dépôt et à la diffusion de documents scientifiques de niveau recherche, publiés ou non, émanant des établissements d'enseignement et de recherche français ou étrangers, des laboratoires publics ou privés. 


\title{
A Conceptual Review of Social Media Adoption in SMEs
}

\author{
Hanaa Namankani ${ }^{1}$, Claire Moxham ${ }^{1 *}$, and Matthew Tickle ${ }^{1}$ \\ ${ }^{1}$ University of Liverpool Management School, Chatham Building, \\ Chatham Street, Liverpool, L69 7ZH, United Kingdom \\ (hanaa, c.moxham, m.tickle)@liverpool.ac.uk
}

\begin{abstract}
Small to Medium Enterprises (SMEs) are not well equipped to use Social Media (SM) and struggle to utilise its full potential in the context of adding value to the business. It is suggested that SMEs often need strategic guidance and support, particularly with regard to optimising SM. The question remains as to how effectively SM is embedded in the business operations of SMEs. This study examines how SM adoption can be realised by SMEs. It considers how SMEs can adapt their business strategies under changing circumstances by adopting $\mathrm{SM}$ in their daily practice. By integrating the current models of technology adoption (including the Technology-Organization-Environment (TOE) and Innovation-DecisionProcess from Diffusion of Innovation (DOI) frameworks) a conceptual framework for achieving SM adoption is developed and presented. The results of this study provide a helpful synthesis of the extant literature and act as a useful springboard for further work in this important area.
\end{abstract}

Keywords: social media, small to medium sized enterprises, technology adoption

\section{Introduction}

This study investigates how Social Media (SM) adoption can enable effective and improved business performance in Small to Medium sized Enterprises (SMEs). The study considers two practical dimensions identified as Technology-Organization-Environment (TOE) and Innovation-DecisionProcess from Diffusion of Innovation (DOI) theories with the aim of exploring the role each theory plays in developing and supporting an environment whereby SMEs can create a sustainable business. A framework for achieving SM adoption is presented which highlights the interaction processes as well as the various stages of developing a SM adoption plan. Important criteria, models and factors 
were considered to evaluate the extant literature, and how SMEs may practically progress from one level to the next in order to keep growing their business. The main objective of this study is to reveal the extent to which SM adoption is applied in SMEs and how it may contribute to the success within SMEs. It is envisaged that the successful implementation of the SM adoption framework will allow SMEs to increase both their flexibility and internal capabilities.

\section{Small to Medium Enterprises (SMEs)}

Although large firms are leading the market in most industries and dominating some industries' market shares, many studies have concluded that the global economy is enhanced by SMEs that are focused, small, innovative and flexible and are run by highly skilled resources, especially IT [1-3]. Additionally, SMEs provide a great opportunity of employment, wide production base and support for large organizations [4]. [3] define a SME as an independent business organization that is run by its owners or part owners and has a small market share, and where the number of employees is not larger than a specific predefined number that slightly differs across nations (mainly between 50 to 500 for medium sized enterprises, and less than 10 or 50 for small enterprises).

The European Commission (EC) Recommendation 96/280/EC [5] presents a slightly different view of SMEs, placing them in the micro, small, and medium-sized enterprises (SMEs) category. This is a set of enterprises that employ less than 250 employees and have an annual turnover estimated at 50 million euro, and/or an annual balance sheet total not exceeding 43 million euro, and are not more than $25 \%$ owned by a non-SME. In addition, the European Commission [5] categorizes SMEs in terms of the number of employees: 0-9 employees is a micro enterprise; 10-99 employees is a small enterprise; and 100-250 employees is a medium enterprise. Nevertheless, no clear evidence or affirmative consensus on the SME definition itself is claimed, as variations occur between countries, industries and even agencies within one country.

Even though the size and market share of SMEs is relatively small, many researchers assert the important contribution they play in the national economy [6]. For instance, in most developed countries in Europe, around $85 \%$ to $99 \%$ of enterprises are considered SMEs if the definition focuses on the number of employee and market share [7]. As a result, the development and sustainability of SMEs has gained significant attention [8], and conducting research to improve this sector of the economy is vital.

\section{Social Media (SM)}

The nature of business and the associated economic environment has frequently changed over time. Mainly within this decade, such change is happening continually and rapidly, thus urging the need for updated studies and research to help organizations understand and effectively react to these changes 
and challenges [9]. One of the most important global changes is the use of SM to achieve the business goals and objectives of maintaining sustainable productivity and competitive advantage [10-12]. According to [13], the adoption of SM is very important to any economic system. Crucially, the utilization of SM is one of the latest examples of the vital role of technology in supporting and changing the business environment $[10,14]$. SM is being considered as one of the effective mediums to reach target audiences of not just business organizations, but any governments, communities, or types of society (e.g. political or social) [15].

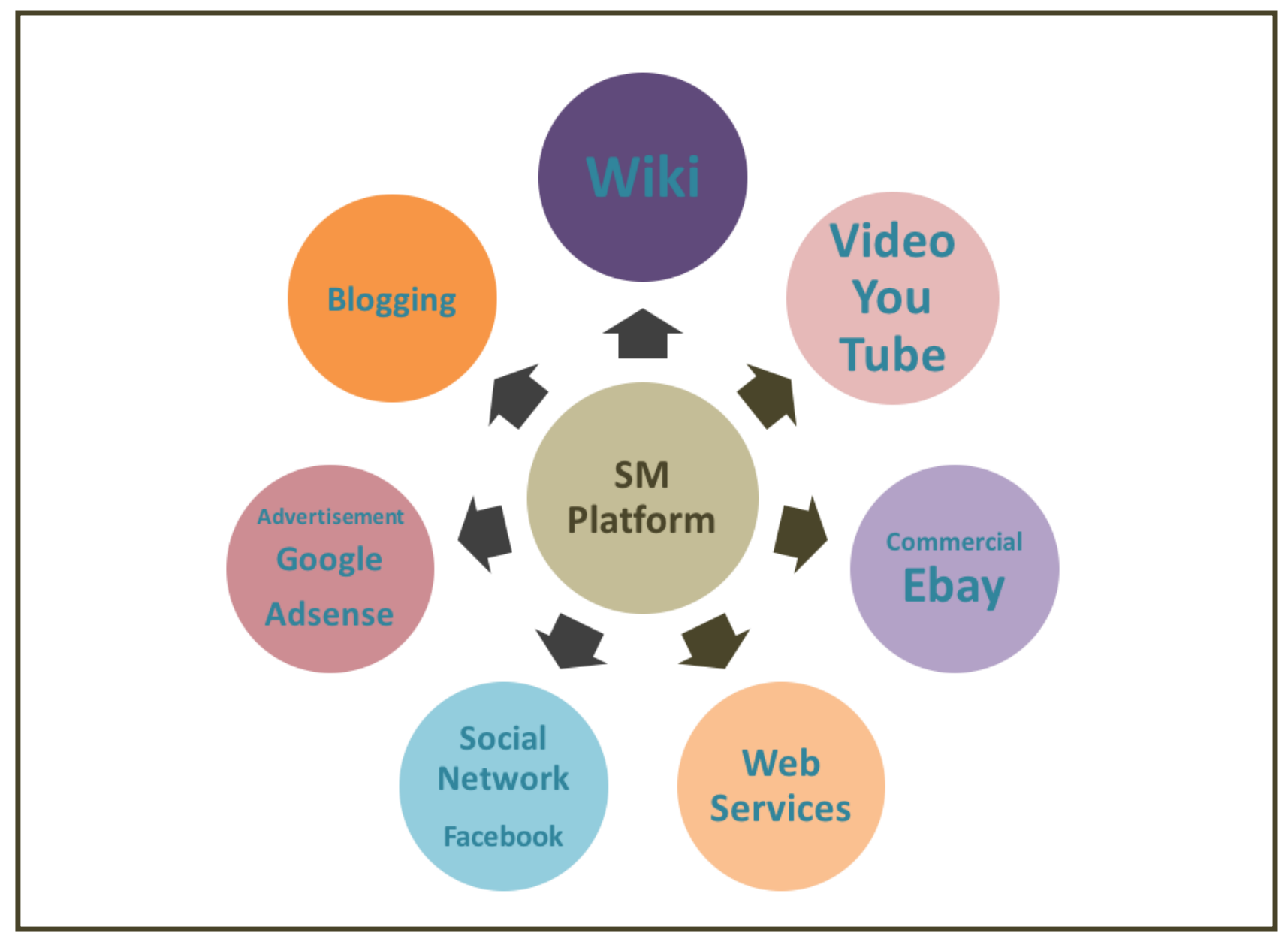

Fig. 1. Social Media Features

Figure 1 details the various features of a SM platform. Studies that examine or research SM phenomena in a business context and SM influence in business are becoming extremely important due to the rapid diffusion of SM globally $[11,16]$ as well as the continuing rise in penetration and access rate of social media $[17,18]$. SM is a widely spread phenomena, however the adoption of SM as part of businesses is still surprisingly slow [19]. Therefore researchers need to investigate the factors affecting SM adoption and develop an understanding of why SM is being slowly adopted by businesses. Appropriate frameworks and models that help organizations in different sectors to adopt and use SM effectively are therefore required. A clear understanding of how SMEs in particular can 
gain SM advantages and benefits and avoid and overcome SM disadvantages and barriers is important $[17,18]$. This study therefore focuses on SM adoption in SMEs and perceives its use as a powerful source and significant factor in improving SMEs performance and productivity [10-12, 20-22].

There are several research studies that have examined SM in the business context; however, these studies mainly focus on the effect of SM on organizations [10] or on the user, with little being known about SM from a company adoption perspective [23]. Also, many studies have looked at SM from a purely marketing perspective [24]. The focus of many studies is mainly concentrated on developed countries, where there is a prevalence of plenty of strong academic research centres and institutions [9]. Only a limited number of studies considered the SME perspective $[25,26]$ and the factors affecting the adoption decision stages, with little or no focus on the implementation and confirmation or after adoption stages [23].

Moreover, there are many unrevealed factors affecting SM adoption by SMEs that need to be discovered and explored, especially in fast growing developing countries [9]. Furthermore, most of the studies in this field preferred the use of quantitative data, mostly from surveys and questionnaires [23], which reflects the need for qualitative research for a deeper analysis and understanding. From the literature review it has been found that there are very few research studies that have been carried out to study SM adoption from the perspective of Saudi Arabian SMEs as a context of a developing country. Accordingly, the objective of this study is to explore and investigate the factors that affect the SM adoption decision process in SMEs in Saudi Arabia; and the extent to which these factors are critical to such adoption and why.

\section{Small Medium Enterprises and Social Media}

Although many research studies have investigated SM and its significance to business, there is still only a vague understanding as to how SMEs can utilize SM adoption effectively [27], particularly as SMEs may not have the budget nor the experience to copy international or large business approaches and strategies [19]. SMEs play a major role in the national and global economy, and it is undeniable that they represent the highest percentage of organizations in almost all developed countries [4].

Some SMEs tend to adopt a new technology, such as SM, for its perceived opportunities and to copy the market trend, yet do not have appropriate how-to-knowledge [28]. Such under-utilization of technology might lead to problems in terms of ineffective adoption and results. Therefore, it is important to explore the impact of a new technology on SMEs as well as how to effectively adopt it in order to avoid any problematic implementation and results [27]. Therefore, SMEs need to prepare for SM adoption by extensively planning operations including finance, marketing, human-resourcemanagement and production [29].

[30] and [31] posit that SMEs can strongly benefit from using SM as it requires minimal cost, 
simple participation and low technological skills. Whereas [31] suggest SM adoption can improve customer relations and business networks, [32] asserts that SMEs believe it is "a must" to adopt SM in business. [33] affirms that the "wait attitude" toward internet technologies adoption decision is no longer valid. As such these points support the argument that SM adoption is a necessary element for SMEs.

\section{Current Models}

Very few studies have looked at SM adoption from the perspective of SMEs [25, 26]. As previously mentioned, there is a shortage of studies examining the factors affecting the adoption decision stages, with no focus on the implementation and confirmation or after adoption stages [23]. To begin to address this shortfall, this study examines the adoption of SM by SMEs. It considers two key theoretical concepts; the Technology-Organization-Environment (TOE) and the Innovation-DecisionProcess from Diffusion of Innovation (DOI). By integrating these dimensions, a conceptual framework for achieving SM adoption is developed and presented. Each of these theoretical concepts is now considered in turn.

\subsection{Technology-Organization-Environment Framework (TOE) Theory}

Developed by [34], the Technology-Organization-Environment (TOE) framework is described as the entire process of innovation. It extended from the development of innovations by engineers and entrepreneurs to the adoption and implementation of those innovations by users within the firm context. [35] suggests that the TOE framework represents one segment of the process on how the firm context influences the adoption and implementation of innovations. In this case this framework represents an organization-level theory that explains the three different elements of a firm's context influencing the adoption decisions and process which are; (i) the technological context, (ii) the organizational context, and (iii) the environmental context. All three contexts are posited to influence the technological adoption in its practical application.

The first context, "Technological" includes all of the technologies that are relevant to the firm which are both (i) technologies that are already in use at the firm, as well as (ii) those that are available in the marketplace but not currently in use. The second context, "The Organizational" refers to the characteristics and resources of the firm, including linking structures between employees, intrafirm communication processes, firm size, and the amount of slack resources. There are several ways in which this context affects adoption and implementation decisions. First, mechanisms that link internal sub-units of the organization or span internal boundaries promote innovation $[36,37]$. The presence of informal linking agents such as product champions, boundary spanners, and gate-keepers is associated with adoption. Besides, cross-functional teams and employees that have formal or 
informal links to other departments or to other value chain partners are additional examples of such mechanisms. Finally the third context "The Environmental" includes the structure of the industry, the presence or absence of technology service providers, and the regulatory environment. Industry structure has been investigated in several ways [35]; for instance, intense competition stimulates the adoption of innovation $[38,39]$. Also, dominant firms within the value chain can influence other value chain partners to innovate [40]. The clear picture of the TOE model is depicted in Figure 2 below.

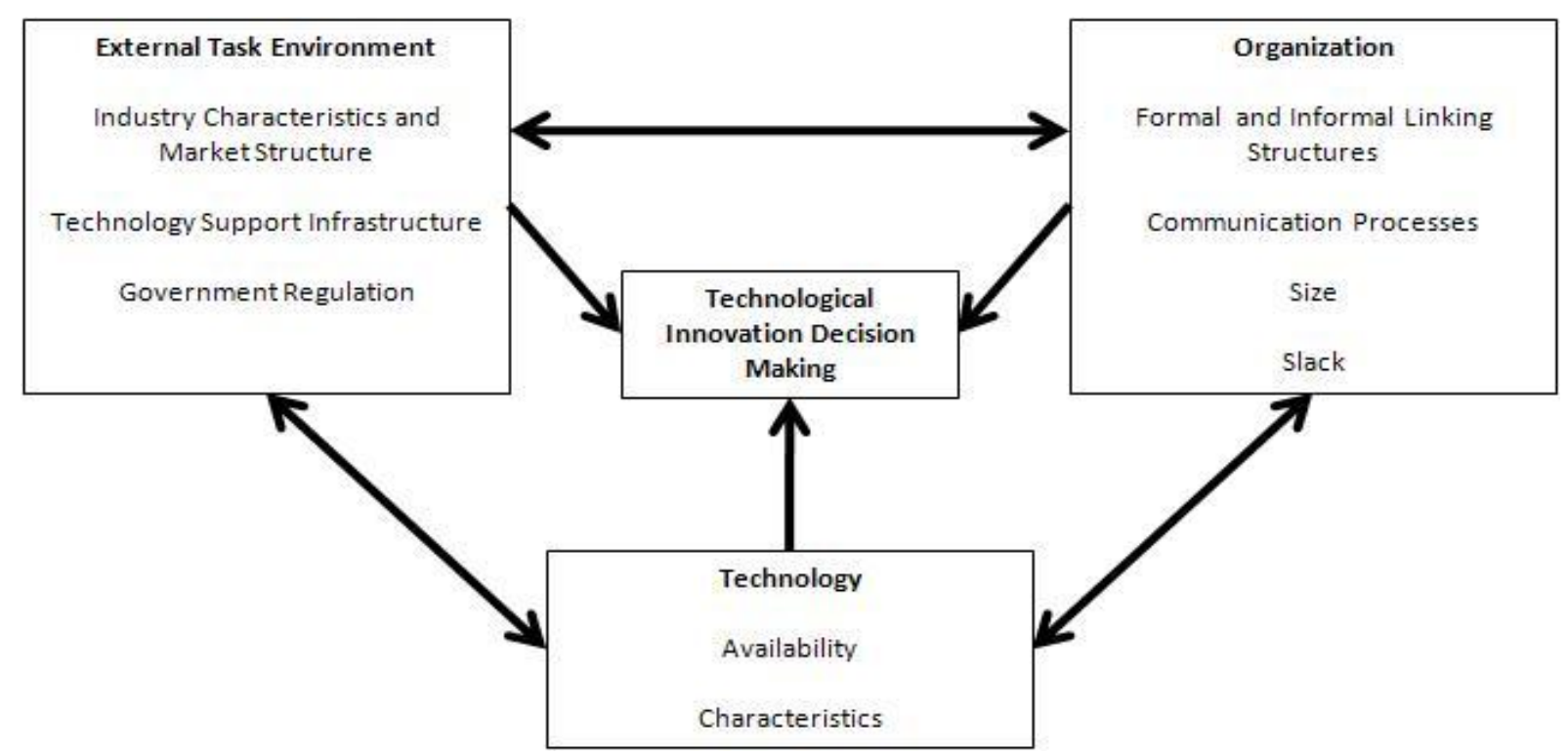

Fig. 2. The technology-organization-environment TOE model framework (Source: [34])

\subsection{Diffusion of Innovation (DOI) Theory}

It is generally accepted that Roger's [41] Diffusion of Innovation (DOI) model is one of the most dominant and inclusive in the technology adoption field. This model is also empirically used and applied in multiple fields, including history, economics, technology and education. In this model, technology is defined as "a design for instrumental action that reduces the uncertainty in the causeeffect relationships involved in achieving a desired outcome" [41:13]. Hardware is defined as "the tool that embodies the technology in the form of a material or physical object" and software is described as "the information base for the tool" [41:259]. Rogers also states that the lower the observability of an innovation such as software, the lower the adoption rate. Again by definition, adoption means "the full use of an innovation as the best course of action available" and rejection is defined as "not to adopt an innovation" [41:177]. Diffusion is "the process in which an innovation is communicated through certain channels over time among the members of a social system" [41:5]. The key concept of DOI is identified as The Innovation-Decision Process, which is described as "an information-seeking and information-processing activity, where an individual/organization is motivated to reduce uncertainty about the advantages and disadvantages of an innovation" [41:172]. 
The innovation-decision process involves five continuous stages in the following order: (i) knowledge, (ii) persuasion, (iii) decision, (iv) implementation, and (v) confirmation.

Firstly "The Knowledge" stage is expressing "what the innovation is and how and why it works" [41:21]. Knowledge composes of three types, which are awareness-knowledge, how-toknowledge, and principles-knowledge. Awareness-knowledge represents the knowledge of the innovation's existence, which can motivate individuals to learn more about the innovation and the other two types of knowledge. The how-to-knowledge contains information about the right and effective way of using the innovation concept. Finally, the principles-knowledge describes the basic popular knowledge of how and why an innovation works as well as how it can be used. Knowledge is crucial in avoiding a lack of continuity later in the process cycle. The second stage "The Persuasion" explains that "The formation of a favourable or unfavourable attitude toward an innovation does not always lead directly or indirectly to an adoption or rejection" [41:176]. The third stage "The Decision" is the critical function to adoption which reflects the "full use of an innovation as the best course of action available" or to reject which means "not to adopt an innovation" [41:177].

The fourth stage, "The Implementation" is the stage where "some degree of uncertainty is involved" [41:6]. Being uncertain regarding the result of the implementation of a new innovation might cause a problem at this stage. This can be handled by involving out-sourced technical experts or specialized change experts. This is one area that this study wishes to address by producing a best practice framework or model of how to adopt a technical innovation (enhancing knowledge at all of its levels); in particular SM adoption within SMEs. In the final stage, "The Confirmation", it is assumed that the adopter will need some form of support for their decision of whether to continue the adoption process or not. The decision to discontinue may be due to the adoption of another better (yet similar) innovation, or due to the innovation becoming less appealing and/or convincing due to its performance during the implementation stage. The DOI model is illustrated in Figure 3 below. 


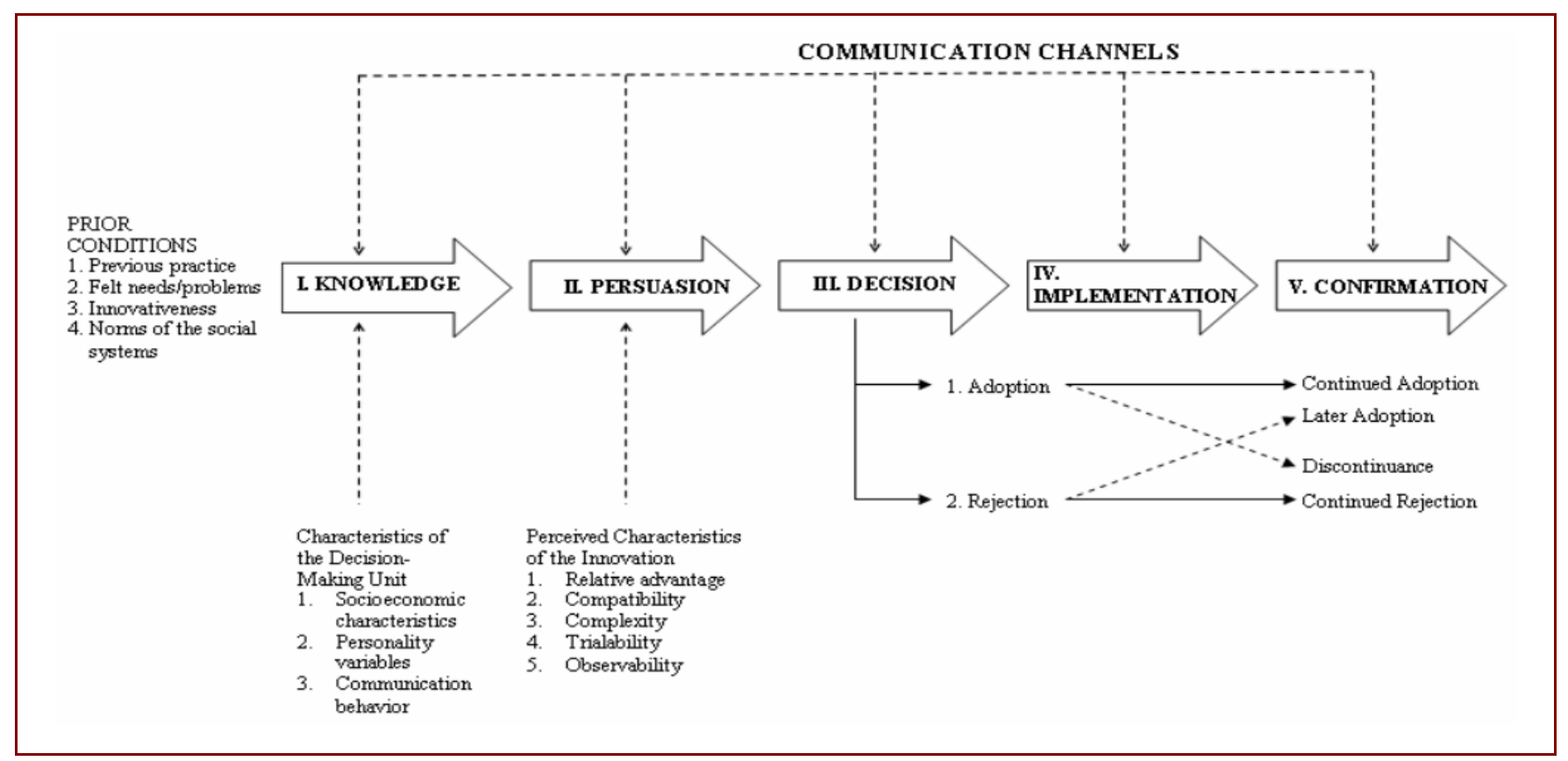

Fig. 3. The Diffusion of Innovation (DOI) model framework (Source: [41])

TOE and DOI are chosen as they remain among the most prominent and widely utilized theories of organizational innovation and technology adoption. In fact [35] believes that TOE is one of the more important future directions in empirical research as this model has been shown to be useful in the investigation of a wide range of innovations and contexts. It is anticipated that these two models, when integrated in the research specific context of SM adoption by SMEs, contributes to the creation of a new model.

\section{The Gap}

The extant literature has shown that the empirical study of SM adoption in SMEs is still lacking. There have been limited studies investigating the influencing factors (either internal or external) that affect the SM adoption decision process in SMEs. It is perceived that the integration of the two existing models of Technology-Organization-Environment (TOE) and Diffusion of Innovation (DOI) will permit robust exploration to address this current shortfall within SMEs. It is anticipated that the DOI will investigate the SMEs decision process and innovation attributes, while the TOE is used to examine the wider context of factors that affect the SM adoption process. The results are therefore expected to offer motivational factors that will benefit SMEs in running their businesses. Subsequently the influencing factors of who, why, and how SM can be effectively adopted can then be revealed further.

Existing models such as TOE [34] and DOI [41] have often been criticised as being too simplistic and offering no clear advice that can be used by SMEs as a form of guidance to motivate them. There are no clear indications of the influencing factors that SMEs need to be aware of or 
avoid, nor are there any suggested critical actions to conduct in order to apply SM adoption successfully. The impact of the successful SM application after the adoption is also not identified. The conundrum remains that the probability of SMEs succeeding in applying SM is not clearly presented; as a result, a gap is identified as exploring the influencing factors of why the SM adoption process is not fully applied within SMEs. The questions persist regarding "how, what and why" the implementation of the SM adoption process is not fully realized in the context of SMEs, when in reality SMEs should have benefited from it to help expedite their business expansion.

\section{Conceptual Framework}

Based on the current models for studying innovation and technology adoption, TOE and DOI were perceived as the most suitable as they provide the ability to look at the adoption process from different perspectives; the adoption decision process and the innovation attributes. The models consist of several theories, thus providing a flexible choice to use the most relevant theories that best serve the research objectives and aim. These models are considered the most appropriate to be used for this study for 2 reasons; firstly, the idea of SM is an innovation in itself, and secondly, this research is looking at the adoption process by SMEs. The DOI model was developed based on Rogers' five stages innovation-decision process model (knowledge, persuasion, decision, implementation, and confirmation). These stages are anticipated as critical in determining the SM adoption process throughout the implementation. The journey of SM adoption can be mapped in these processes. In addition to DOI, TOE contexts are identified as being appropriate to study the adoption of innovation by considering both organizational and environmental factors. These factors are essential for investigating technology adoption by organizations [42]. Organization and environment are used to assess the influencing factors persistent in the organization and surrounding environment. According to [43], "as long as new technologies are developed, and as long as novel contexts for adoption can be identified, the need to understand the adoption of innovation in organizations indicates that the TOE framework is capable of providing insights for researchers and practitioners." Thus, the TOE framework has been combined for a better understanding of the phenomena under investigation.

Figure 4 illustrates the proposed conceptual framework that was developed by integrating the conceptual theory of DOI [41] and TOE [34] to investigate the gap in order to carry out new findings. The DOI model is used to focus on the "five stages model" of innovation adoption decision process consisting of knowledge, persuasion, decision, implementation and confirmation which will look into the SM adoption process stages in SMEs. At this stage the processes will be examined to map the journey of SMEs involved in the SM adoption process. It is assumed that this staged process will contribute to finding answers to the research question of how SM is adopted in SMEs. On the other hand, the TOE framework is viewed from the perspective of the 3 main factors of technology, organization and environment. It is assumed that the contribution will result in the combination of 
internal and external influencing factors that affect the SM adoption progress. Based on this conceptual framework, it is anticipated that the integration of DOI and TOE will begin to address the current gap around the factors that most influence the SM adoption process within SMEs. The result is therefore perceived to be either the effective functional SM adoption or otherwise the rejected slow progress / no changes.

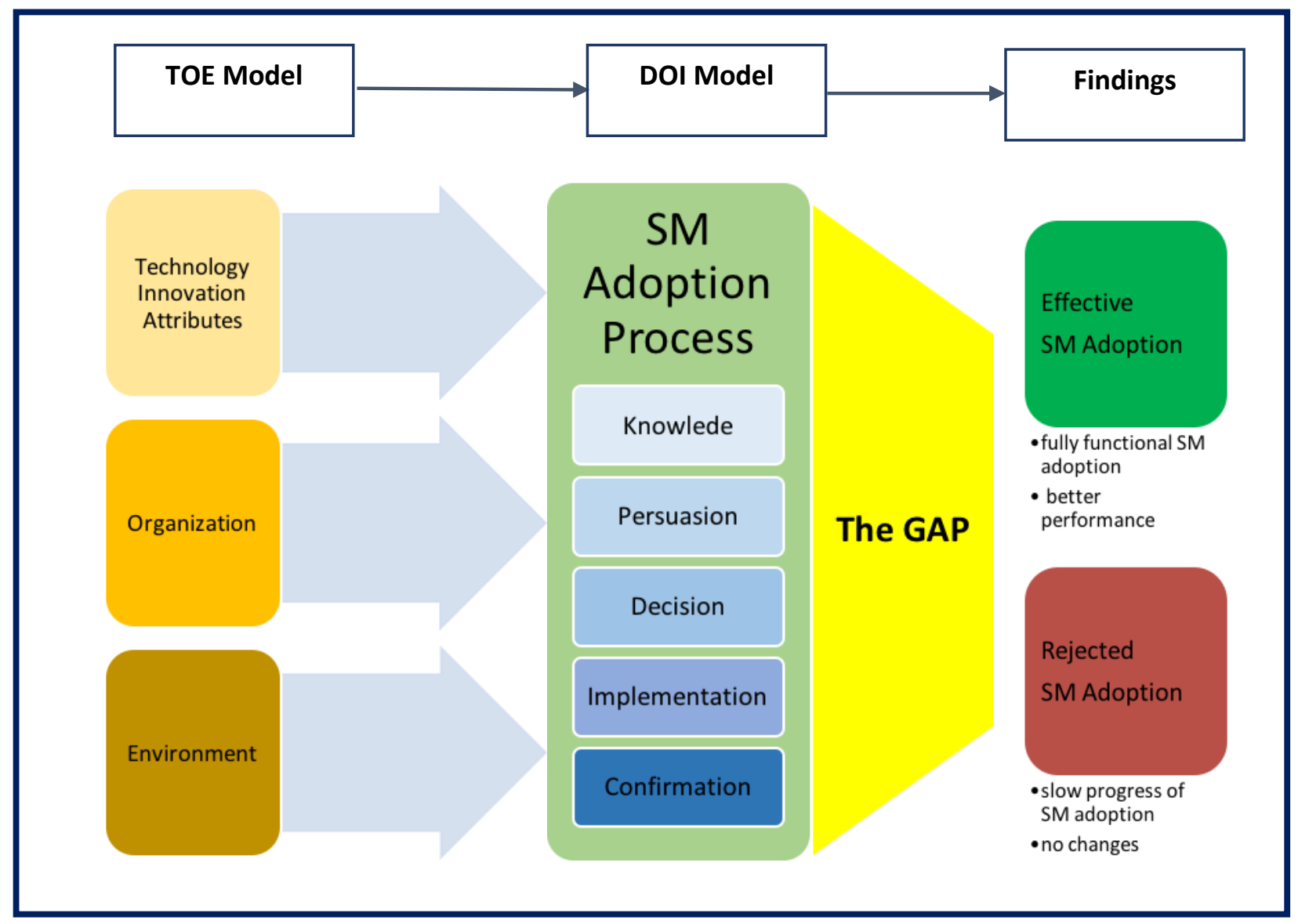

Fig. 4. The Proposed Conceptual Framework

\section{Conclusion}

The findings from the literature revealed concepts and techniques that are believed to be of interest to SMEs as well as to academics and can be explored further. It is anticipated that this study is able to produce some helpful guidance that will add value to SMEs in improving and sustaining their business. The significant contributions of this study are a new conceptual framework and a new paradigm for business within SMEs, both of which can be used to inform policy and practice. It is believed that this framework will be able to assist bodies supporting SMEs in mapping their current state and assessing their ability to potentially move to the next level of business development and sustainability. As such, the main intention of this study is to assist SMEs to sustain / improve their business performance by adopting SM. 


\section{References}

1. McAuley, A.: International Marketing: Consuming Globally, Thinking Locally. John Wiley and Sons Inc, New York (2001)

2. McAuley, A.: Looking back, going forward: Reflecting on research into the SME internationalisation process. Journal of Research in Marketing and Entrepreneurship 12, 21$41(2010)$

3. Bahaddad, A., Al Ghamdi, R., Houghton, L.: To what extent would e-mail enable SMEs to adopt e-commerce? International Journal Of Business and Management 7, 123-132 (2012)

4. Al-Mahdi, H.: Supporting SMEs by universities: An emprical study in Saudi Arabia towards building a conceptual model for best practices. BBS Doctoral Symposium, Brunel University (2009)

5. $\quad$ European Commission: European energy and transport: Trends to 2030. (2003)

6. Fathian, M., Akhavan, P., Hoorali, M.: E-readiness assessment of non-profit, ICT SMEs in a developing country: The case of Iran. Technovation 28, 578-590 (2008)

7. Storey, D.J.: Understanding the Small Business Sector. In: Entrepreneurship, University of Illinois at Urbana-Champaign's Academy for Entrepreneurial Leadership Historical Research Reference in Entrepreneurship (ed.), (1994)

8. Ozmen, E., Oner, A., Khosrowshahi, F., Underwood, J.: SME buying behaviour: Literature review and an application agenda. The Marketing Review 13, 207-227 (2013)

9. Poorangi, M.M., Khin, E.W., Nikoonejad, S., Kardevani, A.: E-commerce adoption in Malaysian Small and Medium Enterprises practitioner firms: A revisit on Rogers' model. Anais da Academia Brasileira de Ciências 85, 1593-1604 (2013)

10. Jagongo, A., Kinyua, C.: The social media and entrepreneurship growth. International Journal of Humanities and Social Science 3, 213-227 (2013)

11. Indrupati, J., Henari, T.: Entrepreneurial success, using online social networking: Evaluation. education, business and society: Contemporary Middle Eastern issues 5, 47-62 (2012)

12. Barnes, N.G., Jacobsen, S.: Adoption of social media by fast growing companies: Innovation amongst the Inc. 500. Journal of Marketing Development and Compeitiveness 7, 11-17 (2013)

13. Nasco, S.A., Toledo, E.G., Mykytyn, P.P.: Predicting electronic commerce adoption in Chilean SMEs. Journal of Business Research 61, 697-705 (2008)

14. Tapscott, D., Williams, A.: Wikinomics: How mass collaboration changes everything. Penguin, New York (2007)

15. Terblanche, N.S.: You cannot run or hide from social media - ask a politician. Journal of Public Affairs 11, 156-167 (2011)

16. Kietzmann, J.H., Hermkens, K., McCarthy, I.P., Silvestre, B.S.: Social media? Get serious! Understanding the functional building blocks of social media. Business Horizons 54, 241-251 (2011)

17. Godes, D., Mayzlin, D.: Firm-created word-of-mouth communication: Evidence from a field test. Marketing Science 28, 721-739 (2009)

18. Godes, D., Mayzlin, D., Chen, Y., Das, S., Dellarocos, C., Pfeiffer, B., Verlegh, P.: The firm's management of social interactions. Marketing Letters 16, 415-428 (2005)

19. Abed, G.T. (ed.): The Palestinian Economy: Studies in development under prolonged occupation. Routledge, Oxon, UK (2015)

20. Brown, S.L., Tilton, A., Woodside, D.M.: The case for on-line communities. The McKinsey Quarterly (2002)

21. Tickle, M., Michaeledes, R., Kehoe, D.: The challenge of creating virtual communities. Information Resources Management Association, Vancouva, Canada (2007)

22. Koch, H., Leidner, D.E., Gonzalez, E.: Digitally enabled social networks: Resolving ITculture conflict. Information Systems Journal 23, 501-523 (2013)

23. Kawaljeet, K., Dwivedi, Y.K., Williams, M.: Rogers' innovation adoption attributes: A systematic review and synthesis of existing research. Information Systems Management 31, 74-91 (2014)

24. Armstrong, G., Kotler, P.: Principles of Marketing. Pearson Prentice Hall, London (2011) 
25. Lee, J.: Adoption of information technology in small business: Testing drivers of adoption for entrepreneurs. Entrue Journal of Information Technology 1, 21-36 (2002)

26. Simpson, M., Docherty, A.J.: E-commerce adoption support and advice for UK SMEs. Journal of Small Business and Enterprise Development 11, 315-328 (2004)

27. Durkin, M., McGowan, P., McKeown, N.: Exploring social media adoption in small to medium-sized enterprises in Ireland. Journal of Small Business and Enterprise Development 20, 716-734 (2013)

28. Drury, G.: Social media: Should marketers engage and how can it be done effectively? Journal of Direct, Data and Digital Marketing Practice 9, 274-278 (2008)

29. Demirbas, D., Hussain, J.G., Matlay, H.: Owner-managers' perceptions of barriers to innovation: Empirical evidence from Turkish SMEs. Journal of Small Business and Enterprise Development 18, 764-780 (2011)

30. Derham, R., Cragg, P., Morrish, S.: Creating value: An SME and Social Media. In: PACIS 2011 Proceedings. (2011)

31. Constantinides, E., Lorenzo-Romero, C., Gómez, M.A.: Effects of web experience on consumer choice: A multicultural approach. Internet Research 20, 188-209 (2010)

32. Durkin, M.: Tweet me cruel: Perspectives on battling digital marketing myopia. The Marketing Review 13, 51-63 (2013)

33. Drew, S.: Strategic uses of e-commerce by SMEs in the east of England. European Management Journal 21, 79-88 (2003)

34. Tornatzky, L.G., Fleischer, M., Chakrabarti, A.K.: Processes of Technological Innovation. Lexington Books, Lexington, MA (1990)

35. Baker, J.: The technoloy-organisation-environment framework. In: Dwivedi, Y.K., Wade, M., Schneberger, S. (eds.) Information Systems Theory: Explaining and Predicting our Digital Society, pp. 231-246. Springer, New York (2011)

36. Galbraith, J.R.: Designing Complex Organizations. Addison-Wesley (1973)

37. Tushman, M., Nadler, D.: Organizing for innovation. California Management Review 28, 74$92(1986)$

38. Mansfield, E.J.: The Economics of Technological Change. Longmans, London (1968)

39. Mansfield, E.J., Rapoport, J., Romeo, A., Wagner, S., Beardsley, G.: Social and private rates of return from industrial innovations. Quarterly Journal of Economics 91, 221-240 (1977)

40. Kamath, R.R., Liker, J.K.: A second look at Japanese product development. Harvard Business Review 72, 154-154 (1994)

41. Rogers, E.: Diffusion of Innovations Free Press, New York (2003)

42. Damanpour, F., Gopalakrishnan, S.: Theories of organisational structure and innovation adoption: The role of environmental change. Journal of Engineering and Technology Management 15, 1-24 (1998)

43. Dwivedi, Y.K., Weerakkody, V., Janssen, M.: Moving towards maturity: Challenges to successful e-government implementation and diffusion. ACM SIGMUS Database 42, 11-22 (2012) 